\title{
Risk Factors of Delayed Milestones Among Children Attending Sohag General Hospital
}

Ekram M. Abdel khalek ${ }^{1}$, Sabra M. Ahmed ${ }^{1}$, Ramadan A.

\author{
Ahmed $^{2}$ \\ and Gamal E. Soliman ${ }^{3}$
}

${ }^{1}$ Public Health and Community Medicine Department, Assiut Faculty of

Medicine

${ }^{2}$ Pediatrics Department, Sohag Faculty of Medicine

${ }^{3}$ Public Health and Community Medicine Department, Al-Azhar Faculty of

Medicine, Assiut branch

Abstract: Developmental delay occurs when a child exhibits a significant delay in the acquisition of milestones or skills, in one or more domains of development (i.e., gross motor, fine motor, speech/language, cognitive, personal/social, or activities of daily living).

Objectives: present study aims to investigate the most common risk factors of The delayed development in children under four years attending Sohag General Hospital.

Subjects and methods: A case control study was conducted in Sohag General Hospital during the period from January 2015 to June 2016 on children attending Pediatric, Physiotherapy and phoniatric clinics in Sohag General Hospital, Sohag Governorate. The sample size was 150 cases and 150 controls. One hundred and fifty children (aged 1.5 month to 48 months) diagnosed with developmental delay by a specialist or/and a developmental pediatrician were recruited as cases.

Results: In the logistic regression model, the odds of developing delayed milestones is significantly higher among children with cyanosis $(\mathrm{OR}=16.391)$, low birth weight $(\mathrm{OR}=6.147)$, parental consanguinity $(\mathrm{OR}=5.489), 1^{\text {st }}$ birth order $(\mathrm{OR}=4.048)$, urban residence $(\mathrm{OR}=3.702)$ and history of neonatal jaundice $(\mathrm{OR}=$ 2.518).

Conclusion: The urban children, first children and from few number of family members were more frequently at risk for developmental delay.

KEY WORDS: Developmental delay, Risk factors, Sohag General Hospital

\section{INTRODUCTION:}

Developmental delay occurs significant delay in the when a child exhibits a acquisition of milestones or 
skills, in one or more domains of development (i.e., gross motor, fine motor, speech/language, cognitive, personal/social, or activities of daily living). A significant delay has been traditionally defined as discrepancy of 25 percent or more from the expected rate, or a discrepancy of 1.5 to 2 standard deviation $[1,2]$.

According to the World Health Organization (WHO), about $5 \%$ of the world's children who were below 14 years of age suffered from moderate to severe Developmental Delay associated disability most of which would have been either prevented or managed, if detected early [3].

In Egypt, a retrospective chart review was carried out on all children referred for developmental assessment in the child development center in the National Institute for NeuroMotor System (NINMS) from July 2001 to April 2002. A total of 1261 patients were identified. Neurodevelopmental

assessment did not confirm developmental delay in 165 cases (13.8\%). While 350 $(28.23 \%)$ cases showed mild developmental delay, 398 $(31.56 \%)$ were moderately delayed and $342(27.12 \%)$ were severely delayed. Positive consanguinity was reported in $43 \%$ of cases [4].
In a study of risk factors and etiology on developmental delay of 18-month-old children in Beijing, China, Zhou and other researchers (2013) found that the prevalence rate of children with developmental delay is $6.91 \%$. The results showed that the main risk factors included were lowincome families, mothers' low educational level, small size for gestational age (SGA) infant, multiple fetuses, serious diseases after birth, congenital malformations and physical retardation [5].

\section{Subjects and methods}

The present study is a matched case-control study. The present study was conducted in Sohag General Hospital on children attending pediatric, Physiotherapy and phoniatric clinics. The sample size was calculated by using the EPI Info 2000 statistical package. The calculation was done using the odds ratio of different risk factors of developmental delay (DD) from previous study (3OR) using 95\% confidence interval and $80 \%$ power of the test and $5 \%$ probability of disease at base line. The calculated sample size is 150 cases and 150 controls.

One hundred and fifty children (aged 1.5 month to 48 months) were diagnosed with developmental delay by a specialist or/and a 
developmental pediatrician were recruited. Patients were referred to the outpatient clinic for etiologic diagnostic evaluation of developmental delay at Sohag General Hospital, which serves as a secondary referral center, serving a region with approximately three million inhabitants.

The cases were compared with 150 age and sex matched normally developed children with no evidence of delay as a control group who selected from children who attended the pediatric clinic in Sohag General Hospital for follow up care and vaccination during the same time period.

Developmental assessment of all children was carried out by using the Denver developmental screening test, 2nd edition. The test is a general screening instrument consists of 125 items divided into four domains: gross motor skills, fine motor/adaptive skills, personal/social, and language skills [6]. Developmental delay is said to exist when a child does not reach developmental milestones at the expected age. Socioeconomic level was calculated by Abd El-Tawab scale [7].

\section{- Exclusion criteria:}

Age under 1.5 months and over 4 years. The actual age registered in the birth certificate was used.

- Other brothers or sisters of a case diagnosed as delayed milestones.

Premature birth with current age under 1 year, children who are premature may not have the same rate of muscle strength and development.

Before starting to collect final data, a pilot study was carried out on 30 patients and some modifications were applied on the questionnaire used.

SPSS version 16.0 was used for description and analysis of data. The Chi-square test and T-test were used. Statistical significance was set at $\mathrm{p}=0.05$. Odds ratios were calculated for risk factors for cases and controls, using Binary Multiple Logistic Regression Analysis.

\section{RESULTS}

This study included 150 cases and 150 controls. Table (1) shows the personal characteristics of the studied children. The mean age for both cases and controls was $31.02 \pm 9.35$ and $30.78 \pm 10.24$ months, respectively. As regards the sex of the children $68.7 \%$ of cases and $70 \%$ of the controls were males. without statistically significant differences.

urban residents cases represented $25.3 \%$ of the cases and $8 \%$ of the controls with statistically significant difference. The Table (1) also shows that there are a statistically significant difference between the cases and the 
controls as regards birth order; the firstborn child was common among the cases $(62.7 \%)$ than the controls $(38.7 \%)$ with statistically significant difference. As regards type of family, $80 \%$ of the cases live in a nuclear family versus $84 \%$ of the controls.

The mean number of family members of the cases and the controls were $3.97 \pm 1.37$ and $4.35 \pm 1.49$, respectively with statistically significant difference.

Table (2) demonstrates some sociodemographic characteristics of parents of the studied children. There is no a statistically significant difference between the cases and the control groups in terms of parents' education and fathers' occupation. As regard mothers work, nearly $9 \%$ of the mothers of the cases were working versus $3.3 \%$ of the mothers of the control with a statistically significant difference. The table shows that there are statistically significant differences between the cases and the control regarding the crowding index and more than half of the cases $(58.7 \%)$ live in a middle socioeconomic level followed by high SES (22\%) then low SES $(19.3 \%)$.

Table (3) shows that there is statistically significant difference between the cases and the controls as regards history of parental consanguinity $(65.3 \%$ versus $43.3 \%)$, preterm $(5.3 \%$ versus $0.7 \%)$, multiple pregnancy $(6.7 \%$ versus $0.7 \%)$, preeclampsia (10\% versus $2.7 \%$ ) and antepartum hemorrhage $(30.7 \%$ versus $51.3 \%)$. On the other hand, parental age, placental position, maternal illness during pregnancy, early exposure to radiation or drugs in the first trimester show no statistically significant differences between cases and their controls $(\mathrm{p}>0.05)$.

Table (4) shows that cesarean section is represented $53.3 \%$ in the cases versus $35.3 \%$ of the controls with statistically significant difference. Also, the Table shows that there are statistically significant differences between the studied cases and their control in the postnatal medical problems as $12.7 \%$ of the cases had a history of cyanosis at birth versus $0.7 \%$ of the controls, $16.7 \%$ of the cases had a history of delayed crying after birth versus $0.7 \%$ of the controls. History of admission into incubator is present in $40.7 \%$ of the cases versus $19.3 \%$ of the controls. Also, $7.3 \%$ of the cases had a history of neonatal convulsions versus $1.3 \%$ of the controls. Also, $26.7 \%$ of the cases had a history of non-feeding during the neonatal period versus $6 \%$ of the controls with statistically significant difference.

Recurrent vomiting is present in $43.3 \%$ of the cases versus $20.7 \%$ of the controls. The table shows that $11.3 \%$ of the cases had a history of difficulty breathing after birth versus $2.7 \%$ of the controls with statistically significant difference.

Table (5) shows that $38 \%$ of the cases had motor developmental delay and couldn't perform the movements that should be done according to their ages. The table also shows that $63.3 \%$ of the cases had speech delay and $2 \%$ of the cases had cognitive delay. Also, table (5) shows that $79.3 \%$ of the cases were first diagnosed by pediatricians while $11.3 \%$ of the cases were first diagnosed by professors, $6 \%$ of the cases were first diagnosed by 
general practitioners and $3.3 \%$ of the cases were first diagnosed by neurologists.

In the logistic regression model (Table 6), the odds of developing delayed milestones is significantly higher among children with cyanosis $(\mathrm{OR}=$ 16.391), low birth weight $(\mathrm{OR}=6.147)$, parental consanguinity $(\mathrm{OR}=$ $5.489), 1^{\text {st }}$ birth order $(\mathrm{OR}=4.048)$, urban residence $(\mathrm{OR}=3.702)$ and history of neonatal jaundice $(\mathrm{OR}=2.518)$.

Table (1): Personal characteristics of the studied children, Sohag General Hospital, 2016

\begin{tabular}{|c|c|c|c|c|c|}
\hline \multirow[t]{2}{*}{ Variables } & \multicolumn{2}{|c|}{$\begin{array}{c}\text { Cases } \\
(n=150)\end{array}$} & \multicolumn{2}{|c|}{$\begin{array}{l}\text { Controls } \\
(n=150)\end{array}$} & \multirow[t]{2}{*}{$\begin{array}{l}\text { P-value } \\
\text {-val }\end{array}$} \\
\hline & No. & $\%$ & No. & $\%$ & \\
\hline \multicolumn{5}{|l|}{ Sex: } & \multirow[t]{3}{*}{0.802} \\
\hline Male & 103 & 68.7 & 105 & 70.0 & \\
\hline Female & 47 & 31.3 & 45 & 30.0 & \\
\hline \multicolumn{5}{|l|}{${ }^{\circ}$ Age: (months) } & \multirow[t]{3}{*}{0.711} \\
\hline Mean \pm SD & \multicolumn{2}{|c|}{$31.20 \pm 9.35$} & \multicolumn{2}{|c|}{$30.78 \pm 10.24$} & \\
\hline Range & \multicolumn{2}{|c|}{$12.0-48.0$} & \multicolumn{2}{|c|}{$12.0-48.0$} & \\
\hline \multicolumn{5}{|l|}{ Residence: } & \multirow[t]{3}{*}{0.000} \\
\hline Rural & 112 & 74.7 & 138 & 92.0 & \\
\hline Urban & 38 & 25.3 & 12 & 8.0 & \\
\hline \multicolumn{5}{|l|}{ Birth order: } & \multirow[t]{5}{*}{0.000} \\
\hline $1 \mathrm{st}$ & 94 & 62.7 & 58 & 38.7 & \\
\hline 2nd-3rd & 31 & 20.7 & 48 & 32.0 & \\
\hline 4th-5th & 13 & 8.7 & 18 & 12.0 & \\
\hline 6th or more & 12 & 8.0 & 26 & 17.3 & \\
\hline \multicolumn{5}{|l|}{ Type of family: } & \multirow[t]{3}{*}{0.367} \\
\hline Nuclear & 120 & 80.0 & 126 & 84.0 & \\
\hline & 30 & 20.0 & 24 & 16.0 & \\
\hline \multicolumn{5}{|l|}{$\begin{array}{c}\text { Number of family } \\
\text { members: }\end{array}$} & \multirow[t]{3}{*}{0.022} \\
\hline Mean \pm SD & \multicolumn{2}{|c|}{$3.97 \pm 1.37$} & \multicolumn{2}{|c|}{$4.35 \pm 1.49$} & \\
\hline Range & \multicolumn{2}{|c|}{$3.0-9.0$} & \multicolumn{2}{|c|}{$3.0-9.0$} & \\
\hline $\begin{array}{c}\text { The child lives } \\
\text { with: }\end{array}$ & & & & & \multirow[t]{3}{*}{0.850} \\
\hline $\begin{array}{c}\text { Father and mother } \\
\text { together }\end{array}$ & \multicolumn{3}{|c|}{ together } & 90.0 & \\
\hline Mother only & 16 & 10.7 & 15 & 10.0 & \\
\hline $\begin{array}{c}{ }^{\beta} \text { Cause of father } \\
\text { absence: }\end{array}$ & & & & & \multirow[t]{3}{*}{0.685} \\
\hline Father's death & 3 & 18.8 & 4 & 26.7 & \\
\hline Father's travel & 13 & 81.3 & 11 & 73.3 & \\
\hline
\end{tabular}

T-test. 
SOHAG MEDICAL JOURNAL Risk Factors of Delayed Milestones Among Children

Table (2): Socio-demographic characteristics of the studied children families,

Sohag General Hospital, 2016

\begin{tabular}{|c|c|c|c|c|c|}
\hline \multirow[t]{2}{*}{ Variables } & \multicolumn{2}{|c|}{$\begin{array}{c}\text { Cases } \\
(n=150)\end{array}$} & \multicolumn{2}{|c|}{$\begin{array}{l}\text { Controls } \\
(n=150)\end{array}$} & \multirow[t]{2}{*}{ P-value } \\
\hline & No. & $\%$ & No. & $\%$ & \\
\hline Father education: & & & & & \multirow{5}{*}{0.190} \\
\hline Illiterate/ Read \& write & 13 & 8.7 & 6 & 4.0 & \\
\hline Basic education & 28 & 18.7 & 33 & 22.0 & \\
\hline Secondary & 23 & 15.3 & 32 & 21.3 & \\
\hline University or higher & 86 & 57.3 & 79 & 52.7 & \\
\hline Mother education: & & & & & \multirow{5}{*}{0.083} \\
\hline Illiterate/ Read \& write & 15 & 10.0 & 14 & 9.3 & \\
\hline Basic education & 65 & 43.3 & 84 & 56.0 & \\
\hline Secondary & 35 & 23.3 & 32 & 21.3 & \\
\hline University or higher & 35 & 23.3 & 20 & 13.3 & \\
\hline Father occupation •: & & & & & \multirow{6}{*}{0.066} \\
\hline Employee & 76 & 50.7 & 71 & 47.3 & \\
\hline Freelancer & 32 & 21.3 & 21 & 14.0 & \\
\hline Farmer & 19 & 12.7 & 18 & 12.0 & \\
\hline Skilled worker & 18 & 12.0 & 23 & 15.3 & \\
\hline Unskilled worker & 5 & 3.3 & 14 & 9.3 & \\
\hline Mother work: & & & & & \multirow{3}{*}{0.033} \\
\hline Housewife & 136 & 90.7 & 145 & 96.7 & \\
\hline Employee & 14 & 9.3 & 5 & 3.3 & \\
\hline Type of house: & & & & & \multirow{3}{*}{0.000} \\
\hline Rent & 32 & 21.3 & 9 & 6.0 & \\
\hline Own & 118 & 78.7 & 141 & 94.0 & \\
\hline Crowding index: & & & & & \multirow{4}{*}{0.049} \\
\hline One per room & 84 & 56.0 & 63 & 42.0 & \\
\hline Two per room & 59 & 39.3 & 76 & 50.7 & \\
\hline More than two per room & 7 & 4.7 & 11 & 7.3 & \\
\hline Father smoking: & & & & & \multirow{3}{*}{0.462} \\
\hline Yes & 97 & 64.7 & 103 & 68.7 & \\
\hline No & 53 & 35.3 & 47 & 31.3 & \\
\hline Smoking among other family member: & & & & & \multirow{3}{*}{0.125} \\
\hline Yes & 3 & 2.0 & 8 & 5.3 & \\
\hline No & 147 & 98.0 & 142 & 94.7 & \\
\hline "Socioeconomic level : & & & & & \multirow{4}{*}{0.017} \\
\hline Low & 29 & 19.3 & 26 & $\mathbf{1 7 . 3}$ & \\
\hline Middle & 88 & 58.7 & 108 & 72.0 & \\
\hline High & 33 & 22.0 & 16 & 10.7 & \\
\hline
\end{tabular}


SOHAG MEDICAL JOURNAL Risk Factors of Delayed Milestones Among Children

Vol. 22 No.1 Jan 2018 Gamal E. Soliman

Table (3): Prenatal risk factors in cases with developmental delay versus controls, Sohag General Hospital, 2016

\begin{tabular}{|c|c|c|c|c|c|}
\hline \multirow[t]{2}{*}{ Variables } & \multicolumn{2}{|c|}{$\begin{array}{c}\text { Cases } \\
(n=150)\end{array}$} & \multicolumn{2}{|c|}{$\begin{array}{l}\text { Controls } \\
(n=150)\end{array}$} & \multirow[t]{2}{*}{ P-value } \\
\hline & No. & $\%$ & No. & $\%$ & \\
\hline${ }^{\circ}$ Maternal age at birth: & \multirow{2}{*}{\multicolumn{2}{|c|}{$26.12 \pm 6.14$}} & & & 0.502 \\
\hline Mean \pm SD & & & \multicolumn{2}{|c|}{$26.59 \pm 5.89$} & \\
\hline Range & \multicolumn{2}{|c|}{17.0 - 44.0} & \multicolumn{2}{|c|}{16.0 - 41.0} & \\
\hline$\circ$ Paternal age at birth: & \multirow{2}{*}{\multicolumn{2}{|c|}{$33.53 \pm 8.28$}} & & & 0.826 \\
\hline Mean \pm SD & & & \multicolumn{2}{|c|}{$33.73 \pm 6.83$} & \\
\hline Range & \multicolumn{2}{|c|}{$21.0-65.0$} & \multicolumn{2}{|c|}{$20.0-67.0$} & \\
\hline Consanguinity among parents: & & & & & \multirow[t]{3}{*}{0.000} \\
\hline Yes & 98 & 65.3 & 65 & 43.3 & \\
\hline No & 52 & 34.7 & 85 & 56.7 & \\
\hline Degree of consanguinity: & & & & & \multirow[t]{3}{*}{0.011} \\
\hline First cousin & 33 & 33.7 & 35 & 53.8 & \\
\hline Second cousin & 65 & 66.3 & 30 & 46.2 & \\
\hline Gestational age: & & & & & \multirow[t]{3}{*}{0.036} \\
\hline Preterm & 8 & 5.3 & 1 & 0.7 & \\
\hline Full term & 142 & 94.7 & 149 & 99.3 & \\
\hline Multiple pregnancy: & & & & & \multirow{3}{*}{0.021} \\
\hline Yes & 10 & 6.7 & 1 & 0.7 & \\
\hline No & 140 & 93.3 & 149 & 99.3 & \\
\hline Placental position: & & & & & \multirow[t]{3}{*}{0.622} \\
\hline Normal & 149 & 99.3 & 147 & 98.0 & \\
\hline Abnormal & 1 & 0.7 & 3 & 2.0 & \\
\hline
\end{tabular}

Table (3) continued:

\begin{tabular}{|c|c|c|c|c|c|}
\hline \multirow[t]{2}{*}{ Variables } & \multicolumn{2}{|c|}{$\begin{array}{c}\text { Cases } \\
(n=150)\end{array}$} & \multicolumn{2}{|c|}{$\begin{array}{l}\text { Controls } \\
(n=150)\end{array}$} & \multirow[t]{2}{*}{ P-value } \\
\hline & No. & $\%$ & No. & $\%$ & \\
\hline \multicolumn{5}{|c|}{ Medical illness during pregnancy: } & \multirow{3}{*}{0.401} \\
\hline Yes & 23 & 15.3 & 18 & 12.0 & \\
\hline No & 127 & 84.7 & 132 & 88.0 & \\
\hline \multicolumn{5}{|c|}{ Preeclampsia: } & \multirow{3}{*}{0.009} \\
\hline Yes & 15 & 10.0 & 4 & 2.7 & \\
\hline No & 135 & 90.0 & 146 & 97.3 & \\
\hline \multicolumn{5}{|c|}{ Radiation exposure during $1^{\text {st }}$ trimester: } & \multirow[b]{3}{*}{1.000} \\
\hline Yes & $\mathbf{0}$ & 0.0 & 1 & 0.7 & \\
\hline No & 150 & 100.0 & 149 & 99.3 & \\
\hline \multicolumn{5}{|c|}{ Taking drugs during first 3 months of pregnancy: } & \multirow{3}{*}{0.357} \\
\hline Yes & 146 & 97.3 & 143 & 95.3 & \\
\hline \begin{tabular}{|l|} 
No \\
\end{tabular} & 4 & 2.7 & 7 & 4.7 & \\
\hline
\end{tabular}


SOHAG MEDICAL JOURNAL

Vol. 22 No.1 Jan 2018
Risk Factors of Delayed Milestones Among Children Gamal E. Soliman

Table (4): Natal and postnatal risk factors in the cases versus the controls, Sohag General Hospital, 2016

\begin{tabular}{|c|c|c|c|c|c|}
\hline \multirow[t]{2}{*}{ Variables } & \multicolumn{2}{|c|}{ Cases $(n=150)$} & \multicolumn{2}{|c|}{$\begin{array}{c}\text { Controls } \\
(n=150)\end{array}$} & \multirow[t]{2}{*}{ P-value } \\
\hline & No. & $\%$ & No. & $\%$ & \\
\hline \multicolumn{5}{|l|}{ Mode of delivery: } & \multirow{3}{*}{$0.000 *$} \\
\hline Normal & 70 & 46.7 & 97 & 64.7 & \\
\hline Caesarean & 80 & 53.3 & 53 & 35.3 & \\
\hline \multicolumn{5}{|l|}{ Delivery assisted by: } & \multirow{3}{*}{0.149} \\
\hline Physician & 125 & 83.3 & 115 & 76.7 & \\
\hline Midwife & 25 & 16.7 & 35 & 23.3 & \\
\hline \multicolumn{5}{|l|}{ Place of delivery: } & \multirow{4}{*}{0.335} \\
\hline Hospital & 84 & 56.0 & 75 & 50.0 & \\
\hline Private clinic & 41 & 27.3 & 40 & 26.7 & \\
\hline Home & 25 & 16.7 & 35 & 23.3 & \\
\hline \multicolumn{5}{|l|}{ Problem during delivery: } & \multirow{3}{*}{0.258} \\
\hline Yes & 13 & 8.7 & 8 & 5.3 & \\
\hline No & 137 & 91.3 & 142 & 94.7 & \\
\hline \multicolumn{6}{|l|}{ Problem after delivery •: } \\
\hline Did not cry directly & 25 & 16.7 & 1 & 0.7 & 0.000* \\
\hline Cyanosed & 19 & 12.7 & $\mathbf{1}$ & 0.7 & $0.000 *$ \\
\hline LBW (less than $2.5 \mathrm{~kg}$ ) & 81 & 54.0 & 23 & 15.3 & $0.000 *$ \\
\hline Difficulty breathing & 17 & $\mathbf{1 1 . 3}$ & 4 & 2.7 & $0.003 *$ \\
\hline \multicolumn{5}{|l|}{ Admission into incubator: } & \multirow{3}{*}{$0.000 *$} \\
\hline Yes & 61 & 40.7 & 29 & 19.3 & \\
\hline No & 89 & 59.3 & 121 & 80.7 & \\
\hline \multicolumn{6}{|c|}{ Problems during neonatal period •: } \\
\hline Jaundice & 124 & 82.7 & 122 & 81.3 & 0.764 \\
\hline Recurrent vomiting & 65 & 43.3 & 31 & 20.7 & $0.000^{*}$ \\
\hline Non-feeding & 40 & 26.7 & 9 & 6.0 & $\overline{0.000 *}$ \\
\hline Convulsions & 11 & 7.3 & 2 & 1.3 & 0.011* \\
\hline \multicolumn{5}{|c|}{ Breast feeding in the first half hour: } & \multirow[t]{3}{*}{ 0.001* } \\
\hline Yes & 57 & 38.0 & 86 & 57.3 & \\
\hline No & 93 & 62.0 & 64 & 42.7 & \\
\hline
\end{tabular}

- More than one problem may be found

Table (5): Distribution of delayed milestone cases, Sohag General Hospital, 2016

\begin{tabular}{|l|c|c|}
\hline \multirow{2}{*}{ Variable } & \multicolumn{2}{|c|}{$\begin{array}{c}\text { Cases of delayed milestone } \\
(\mathbf{n}=150)\end{array}$} \\
\cline { 2 - 3 } & No. & $\%$ \\
\hline Diagnosis: & & \\
\hline Motor & 57 & 38.0 \\
\hline Speech & 95 & 63.3 \\
\hline Cognitive & 3 & 2.0 \\
\hline \hline The person who diagnosed him first time: & & \\
\hline General practitioner & 9 & 6.0 \\
\hline Pediatrician & 119 & 79.3 \\
\hline Professor (pediatric or phoniatrician) & 17 & 11.3 \\
\hline Neurologist & 5 & 3.3 \\
\hline
\end{tabular}


Table (6): Logistic regression of the delayed milestones among the studied children, Sohag Governorate, 2016

\begin{tabular}{|l|c|c|}
\hline & OR $(95 \%$ C.I. $)$ & P-value \\
\hline Residence in Urban area & $3.702(1.203-11.389)$ & $0.022 *$ \\
\hline Birth order $\left(r: 6^{\text {th }}\right.$ or more) & & \\
\hline $1^{\text {st }}$ & $4.048(1.450-11.299)$ & $0.008 *$ \\
\hline $2^{\text {nd }}-3^{\text {rd }}$ & $1.959(0.692-5.545)$ & 0.206 \\
\hline $4^{\text {th }}-5^{\text {th }}$ & $1.832(0.535-6.272)$ & 0.335 \\
\hline Mother work $^{*}$ & $4.115(0.942-17.982)$ & 0.060 \\
\hline Consanguinity $^{*}$ & $5.489(2.769-10.883)$ & $0.000 *$ \\
\hline Cyanosed & $16.391(1.453-184.939)$ & $0.024 *$ \\
\hline LBW & $6.147(3.075-12.286)$ & $0.000 *$ \\
\hline Jaundice & $2.518(1.166-5.440)$ & $0.019 *$ \\
\hline
\end{tabular}

\section{DISCUSSION:}

This study reveals that $68.7 \%$ of cases were males and $31.3 \%$ of the cases and were females (Table 1) and this is consistent with previous studies which revealed that girls had better neurodevelopmental outcomes in cognitive development, acquisition of both receptive and expressive communication skills, fine motor and socialemotional development. This finding is partially consistent with the results of previous studies which found that girls tend to perform better than boys on cognitive and language tasks [8-9]. A Swedish study of more than 1000 children showed significant differences in favor of girls' verbal comprehension and production [10]. In a study conducted in Crete, Greece differences found between males and females in fine motor and social emotional development.

The results provide evidence that residence is significantly associated with delayed development of the child. This is consistent with the study conducted for comparison of normal developmental milestones among urban and rural children in Madina, Saudi, Arabia [11].

This study revealed that $19.3 \%$ of the cases were of low socioeconomic level versus $17.3 \%$ of the controls (Table 2) and this is consistent with a previous study conducted by Horwitz (2003) [12] which reported that children who come from families characterized by a low 
educational level and poverty are more likely to experience delays and difficulties in expressive language. Certainly, this does not mean that the low socioeconomic level of the family per se directly affects language development, but rather that the mechanisms and conditions that define this level affect the process of language development to an extent. High-educated mothers are more likely to use rich vocabulary and speak in longer utterances when interacting with their children. Thus, children coming from a high socioeconomic background develop the size of their productive vocabulary more than children who come from a lower socioeconomic status.

This study shows that fetal exposure to preeclampsia was significantly associated with development of DD in children from the study (Table 3) and the association was more robust in those pregnancies complicated by severe disease. Preeclampsia was associated with DD primarily in severe presentations that involved placental insufficiency. $10 \%$ of the cases were born after pregnancies complicated by pre-eclampsia versus $2.7 \%$ of the controls with statistically significant difference. The results of this study are consistent with another study found strong associations between preeclampsia and Autism Spectrum Disorder (ASD) that increased with presentation severity; a significant association between severe preeclampsia and/or placental insufficiency and DD was confirmed [13].

As regards the birth order, this study revealed that the first child was common in the cases than the controls (Table 1). This is against studies which revealed that first-born children experience an early social and language environment which is different from that experienced by laterborn children, with greater possibilities for communicative interaction with an adult [14]. Birth order has been shown to be a risk factor for vocabulary delay in two-year-old children [15].

The findings of this study indicated that having older siblings at home showed a positive impact on cognitive, receptive and expressive communication skills and gross motor (Table 1) which revealed that older siblings provide developmentally more advanced models for younger siblings and help create a stimulating, enriched environment that seems to enhance younger siblings' development in terms of 
cognitive, language, and motor development [16]. However, this finding are consistent with studies supporting that, in the presence of an older sibling, younger siblings' opportunities to participate in conversations are diminished. A possible explanation for this finding could be that maternal attention being spread over a couple of children may mean mothers are less responsive to each child's particular needs.

It was found that $9.3 \%$ of the mothers of the cases were employed compared $3.3 \%$ of controls. Mechanisms for understanding how early maternal employment might affect children are offered by attachment theory [17]. In Greece, there is a possibility for a flexible leave policy for employed mothers in the public sector especially, which allows them to stay at home or reduce the working hours during the first year of a child's life. In few cases, however, mothers returned to work sooner because of various reasons (e.g. selfemployed mothers).

Early maternal employment initiates a cascade of early starting and long-lasting care by others [18] such as grandparents, other family members, baby-sitters, nursery, etc. A later return to work offers infants the opportunity to establish an attachment relationship with their mothers, which is consequential for later cognitive development and behavior [19]. With a later start of mother's employment research findings show a more mixed picture with some negative, but also positive effects. Nomaguchi [20] showed that maternal employment when the child is four years old has a range of positive impacts, including a decreased level of hyperactivity, aggression and anxiety and also more prosocial behavior.

Essentially all intrapartum complications are more common in twin pregnancies [21] and many intrapartum complications are associated with major and minor developmental disabilities and this is consistent with this study which revealed that $6.7 \%$ of the cases were twins or multiple pregnancies compared to $0.7 \%$ of the controls with statistically significant difference.

The presence of fetal distress during labor was characteristic of the delayed group. This suggests an association with anoxia and/or placental deficiency, evidence of which was found in the cohort study [22].

The simultaneous presence of anoxia before birth has been 
shown to produce neurological consequences in animal offspring and could therefore be a potential source of injury to neonates [23]. Moreover, most of studies have showed developmental delay was common in children born preterm [24-25]. Our finding is consistent with these studies where preterm delivery is a significant risk factor for delayed milestones.

Children with chronic lung disease and pneumonia in neonatal period were more likely to have developmental delays than normal children. This finding is consistent with other researches showing the relationship between long chronic lung disease and poorer IQ scores in formerly premature school-age children, suggesting the anoxia after birth may also cause mild brain damage that may result in developmental delays [25].

Moreover, this study revealed that children with developmental delays more likely experienced the newborn pathological jaundice than the normal group. This is consistent with other studies which demonstrated that free or unbound bilirubin (or bilirubin not bound to protein) is associated with bilirubininduced neurotoxicity in term or preterm infants [26].
According

to its pathogenesis, free bilirubin could cross blood-brain barrier and cause brain injury which may induce the children's motor impairment. The present study also found that LBW (less than 2500 gm.) was significantly associated with an increased risk for all delayed developmental milestones, consistent with a large number of previous studies [27].

The current study revealed a high rate of caesarean deliveries $(53.3 \%$ among the cases of the present study) compared with $35.3 \%$ among controls, as suggested by previous studies in Crete [28] and elsewhere in Greece [29], as well. A caesarean section is usually performed in an obstetric emergency, where complications of a vaginal delivery would put the baby's or mother's life or health at risk. In Greece, several medical and non-medical factors have been implicated to this increase in caesarean deliveries such as previous caesarean deliveries dystocia, pathological fetal heart rate [29], fetal distress, breech presentation, maternal body mass, birth weight, following in vitro fertilization, as well as socio-economic factors (e.g. type of delivery hospital, type of insurance) and convenience incentives (i.e. increasing 
caesarean section rates during the "working" hours of the day for the physicians, etc.).

The preterm deliveries in this study $(5.3 \%$ for the cases versus $0.7 \%$ for the controls) were significantly associated and strong predictors of delayed milestones. This result was in agreement with other studies which stated that the rate of preterm deliveries is ranging between $(5-7 \%)$ of live births in some developed countries, but are estimated to be substantially higher in developing countries [30].

Prematurity was significantly associated with lower neurodevelopmental scores in terms of infants' receptive communication, and twins tended to score lower in cognitive, fine motor and Social-Emotional Scales. Marked differences are seen in neurological and health status, intellectual functioning, school performance and behavior between children born prematurely compared to those born at term [31]. Bhutta [32] demonstrated that preterm infants have lower cognitive scores than full-term controls, which are correlated with birth weight and gestational age. In this study, infants' birth weight was found to be positively correlated with cognitive, expressive communication, fine and gross motor development (Table 4).

Del Bono and Ermisch (2009) [33] showed that birth weight has significant but very small effects on children's cognitive development at the age of three years old. In this study, consanguineous marriage was found in $65.3 \%$ of the cases compared to those born to mothers with no blood relation to their husbands (34.7\%). This is consistent with other studies revealed that mild and severe intellectual and developmental disability are present at higher frequency in consanguineous families [34].

Conclusion

and

\section{Recommendations:}

Developmental delay is associated with:

- Children with cyanosis (OR $=16.391$ ).

- Low birth weight $(\mathrm{OR}=$ 6.147).

- Parental consanguinity (OR $=5.489$ ).

- $1^{\text {st }}$ birth order $(\mathrm{OR}=4.048)$.

- Urban residence $(\mathrm{OR}=$ 3.702).

- History of neonatal jaundice $(\mathrm{OR}=2.518)$.

Based on the results, the present study recommends the followings:

Early identification and referral of children at risk or suspected of disability by primary referral sources 
(including physicians and other health care providers). Improving the quality of antenatal, natal, perinatal and postnatal care in the health facilities and promotion of breast feeding for improving infant's health outcomes.

Early diagnosis and proper management of difficulty breathing, cyanosis, low birth weight and neonatal jaundice to avoid their longterm complications. Improvement of socioeconomic conditions of the population to prevent or reduce all negative health outcomes.

\section{References}

1. Accardo PJ, Whitman BY, Behr SK, Farrell A, Magenis E and MorrowGorton J (2003): Dictionary of developmental disabilities terminology. 2nd edition. Brookes Publishing Co.

2. Tervo R (2003): Identifying patterns of developmental delay can help diagnose neurodevelopmental disorders. Pediatrics Perspective, 12 (3):1.

3. World Health Organization (2008): The global burden of disease: 2004 update. Geneva: World Health Organization Press.

4. El Meliegy E and Hossam El Sabbagh M (2004): Etiology of developmental delay in Egyptian children. Int. J. Ch. Neuropsychiatry, 1(1): 29-40.

5. Zhou WJ, Liang AM, Wang FZ, Cui WH, Wang XY, Liu QM, You H, He CY, Peng JR, Zhang YW, Yu C, Huang QH, Guo MM, Ji TY, Sang T, Yang YL, Zhu SN, Wang JM and Jiang YW (2013): Epidemiological study on developmental delay of 18month-old children from four districts/counties in Beijing. Beijing Da Xue Xue Bao, 45(2):211-216.

Service Delivery. Chicago: University of Chicago Press.

6.Frankenburg WK, Dodds J, Archer P (1992): The DENVER II: A major revision and restandardization of the Denver Developmental Screening Test. Pediatrics, 89:91-97.

7- Abd El-Tawab Abd El-Ah (2004): Family socio-economic scale. Journal of Faculty of Education, Assiut University. 20(2).

8. Cornish AM, McMahon CA, Ungerer JA, Barnett B, Kowalenko $\mathrm{N}$ and Tennant $\mathrm{C}$ (2005): Postnatal depression and infant cognitive and motor development in the second postnatal year: The impact of depression chronicity and infant gender. Infant Behavior and Development, 28 (4): 407417.

9. Hops H (1995): Age- and gender-specific effects of 
parental depression: A commentary. Developmental Psychology, 31 (3): 428-431.

10. Communicative skills in relation to gender, birth order, childcare and socioeconomic status in 18-month-old children. Scandinavian Journal of Psychology, 46 (6):485-491.

11. Salih SA, Hassan B(1998): Normal developmental milestones. Saudi Medical Journal. 19:244-248

12. Horwitz SM, Irwin JR, BriggsGowan MJ, Bosson Heenan JM, Mendoza $\mathrm{J}$ and Carter AS (2003): Language delay in a community cohort of young children. Journal of American Academy of Child and Adolescent Psychiatry, 42: 932-940.

13. Walker CK, Ashwood P, Hertz-Picciotto I (2015): JAMA Pediatr, 169(6):606-7.

14. Hoff E (2003): The specificity of environmental influence: Socioeconomic status affects early vocabulary development via maternal speech. Child Development, 74 (5):13681378.

15. Zubrick SR, Taylor KL, Rice ML and Slegers DW (2007): Late language emergence at 24 Months: An epidemiological study of prevalence, predictors, and covariates. Journal of Speech, Language and Hearing Research, 50: 1562-1592.

16. Berger SE and Nuzzo K (2008): Older siblings influence younger siblings' motor development. Infant and Child Development, 17 (6): 607-615.

17. Bowlby J (1969): Attachment and loss : 1. Attachment. New York: Basic Books.

18 Belsky J (2001):

Developmental risks (still) associated with early child care. Journal of Child Psychology and Psychiatry, 42: 845-859.

19. Thompson RA (2008): Early attachment and later development: Familiar questions, new answers. (Vol. Eds.), Handbook of attachment: Theory, research, and clinical applications (2nd ed.,). New York, NY: Guilford Press, 2: 348-365.

20. Nomaguchi KM (2006): Maternal employment, nonparental care, mother-child, interactions, and children's outcomes during preschool years. Journal of Marriage and Family, 68 (5): 1341-1369.

210 Creasy RK, Resnik R and Iams J (Eds.) (2004): Maternalfetal medicine (5th ed.). Philadelphia: Saunders.

22. Hultman CM, Sparen $P$ and Cnattangius S (2002): Perinatal risk factors for infantile autism. Epidemiology, 13: 417-423.

23. Hultman CM, Sparen $\mathrm{P}$ and Cnattangius S (2002): Perinatal risk factors for infantile autism. Epidemiology, 13: 417-423. 
24. Davis NM, Ford GW, Anderson PJ and Doyle LW (2007):

Developmental coordination disorder at 8 years of age in a regional cohort of extremely-lowbirthweight or very preterm infants. Developmental Medicine \& Child Neurology, 49: 325-330.

25. Holsti L, Grunau RV and Whitfield MF (2002): Developmental coordination disorder in extremely low birth weight children at nine years. Journal of Developmental \& Behavioral Pediatrics, 23: 915.

26. Ahlfors CE, Amin SB and Parker AE (2009): Unbound bilirubin predicts abnormal automated auditory brainstem response in a diverse newborn population. Journal of Perinatology, 29: 305-309.

27.Strauss RS and Dietz WH (1998): Growth and development of term children born with low birth weight: effects of genetic and environmental factors. Journal of Pediatrics, 133: 67-72.

28. Papaioannou A, Patelarou E, Chatzi L, Koutis A, Kafatos A and Kogevinas M (2008): Use of healthcare services and risk factors among pregnant women in Crete. International Journal of Gynaecology \& Obstetrics, 103 (3): 253-255.
29. Dinas K, Mavromatidis G, Dovas D, Giannoulis C, Tantanasis $\mathrm{T}$ and Loufopoulos A (2008): Current caesarean delivery rates and indications in a major public hospital in northern Greece. The Australian and New Zealand Journal of Obstetrics and Gynaecology, 48 (2): 142-146.

30.Mathews TJ and MacDorman MF (2010): Infant mortality statistics from the 2006 period linked birth/infant death data set. Nat Vital Stat Rep, 58:131 .

31.Salt A and Redshaw M (2006): Neurodevelopmental follow-up after preterm birth: Follow up after two years. Early Human Development, 82 (3): 185-197.

32. Bhutta AT, Cleves MA, Casey $\mathrm{P}$, Cradock MM and Anand KJ (2002): Cognitive and behavioral outcomes of schoolaged children who were born preterm: A meta-analysis. JAMA: The Journal of the American Medical Association, 288 (6): 728-737.

33. Del Bono $\mathrm{E}$ and Ermisch $\mathrm{J}$ (2009): Birth weight and the dynamics of early cognitive and behavioral development. IZA Discussion, 4270.

34.Bittles AH (2001): Consanguinity and its relevance to clinical genetics. Clin Genet, 60: 89-98. 